\title{
Uso do plasma suíno ultrafiltrado na recuperação de leitões com sinais clínicos de circovirose
}

[The use of ultra-filtered swine plasma in the recovery of pigs with clinical signs of porcine circovirus infection]

\author{
N. Morés ${ }^{1}$, A.L. Amaral ${ }^{1}$, J.R.C. Zanella ${ }^{1}$, A. Cordebella ${ }^{2}$, L.C. Bordin ${ }^{1}$, S. Oliveira ${ }^{1}$ \\ D. Gava $^{3}$, L.F.S. Rangel \\ ${ }^{1}$ Embrapa Suínos e Aves \\ Cx. Postal 21 \\ 89700-000 - Concórdia, SC \\ ${ }^{2}$ Copérdia - Concórdia, SC \\ ${ }^{3}$ CIDASC - Concórdia, SC \\ ${ }^{4}$ APC do Brasil - São Paulo, SP
}

\begin{abstract}
RESUMO
Testou-se o efeito do plasma suíno ultrafiltrado spray-dried, associado a um acidificante comercial na água de bebida para a recuperação de leitões com sinais clínicos da síndrome multissistêmica do definhamento dos suínos (SMDS). Utilizaram-se 40 leitões com sinais clínicos da SMDS, selecionados 20 dias após o alojamento em uma unidade de terminação, distribuídos em quatro tratamentos (T) de 10 leitões cada. No T1, os animais receberam água clorada à vontade (controle); no T2, solução com 2,5\% do plasma sangüíneo diluído em água; no T3, acidificante $\left(\right.$ Selko $^{\circledR}$ ) diluído em água na dosagem de $12 \mathrm{ml} / 101$ e, no T4, solução com $2,5 \%$ do plasma sangüíneo e o acidificante na dose de $12 \mathrm{ml} / 101$, diluídos em água. Os leitões não foram medicados e foram sacrificados aos 28 ou 40 dias de experimento para avaliação sorológica e patológica. Não houve diferença no ganho de peso e na situação clínica-patológica entre os tratamentos. Entretanto, os leitões do T4 estavam em melhor situação clínica-patológica. Os leitões dos quatro tratamentos tiveram boa recuperação, sem terem sido medicados. Observou-se alta freqüência de lesões compatíveis com a SMDS nos pulmões, rins e linfonodos. Concluiu-se que o plasma spray dried associado ao ácido não melhoraram o desempenho e a situação clínicapatológica de leitões com sintomas da SMDS.
\end{abstract}

Palavras-chave: suíno, plasma suíno, síndrome multissistêmica do definhamento, circovirus suíno tipo 2

\begin{abstract}
The effect of the ultra-filtered spray-dried porcine plasma, associated to a commercial acid in the drinking water was tested for recovering pigs with clinical signs of the porcine postweaning multisystemic wasting syndrome (PMWS). Forty piglets with clinical signs of the PMWS were used following a selection at 20 days after their housing in one finishing facility. They were divided in four treatment groups (T) of 10 pigs each: T1 - chlorine treated water ad libitum (control); T2 - solution prepared with 2.5\% of plasma diluted in water; T3 - acid (Selko (B) diluted in water at the concentration of $12 \mathrm{ml} / 10 \mathrm{l}$; T4 - solution prepared with 2.5\% of plasma diluted and the acid (Selko $(\mathbb{R})$ diluted in water at the concentration of $12 \mathrm{ml} / 10 \mathrm{l}$. The pigs received no medication and were euthanized at 28 or 40 days after the beginning of the experiment for serological and pathological tests. Differences at the weight gain and in the clinical-pathological situation were not observed among the treatments. However, pigs from T4 were in better clinical-pathological situation. The pigs of all four treatments showed a good recovery, although they were not medicated. Even though, it was observed a high frequency of lesions compatible to PMWS in the lungs, kidneys and lymph nodes. It was concluded that the plasma spray-dried associated to the acid did not improve the performance and the clinical-pathological situation of pigs with clinical signs of PMWS.
\end{abstract}

Keywords: pig, porcine plasma, postweaning multisystemic wasting syndrome, porcine circovirus type 2

Recebido em 3 de novembro de 2005

Aceito em 4 de abril de 2007

E-mail: mores@cnpsa.embrapa.br 


\section{INTRODUÇÃO}

A circovirose suína é causada pelo circovirus suíno tipo 2 (PCV2), agente infeccioso associado à ocorrência da sindrome multissistêmica do definhamento dos suínos (SMDS) e a outras formas de manifestação clínica (Zanella e Morés, 2003). No Brasil, a SMDS foi diagnosticada em 2000 (Zanella e Morés, 2000). A partir de 2001, a SMDS tem se manifestado de forma endêmica em muitas criações de suínos do Brasil, ocasionando prejuízos significativos (Morés, 2005). Os principais sinais clínicos observados na SMDS são apatia, febre, anorexia, anemia/icterícia, definhamento, dispnéia, diarréia e, às vezes, dermatite, associados a um quadro patológico de adenopatia, depleção linfóide e inflamação linfo-histiocitária em vários órgãos (Harding et al., 1998; Zanella e Morés, 2003). As taxas de morbidade e mortalidade variam de 70 a $80 \%$ e de 4 a $30 \%$, respectivamente, e afetam predominantemente leitões entre 5 a 12 semanas de idade. O controle da SMDS é difícil e muitas vezes frustrante. Atualmente, não existe vacina comercial, e o controle baseia-se na identificação e na correção dos fatores que favorecem sua ocorrência (Madec et al., 1999).

Vários estudos têm demonstrado que o plasma animal spray-dried adicionado à dieta de leitões desmamados melhora o ganho de peso, o consumo de alimento e a eficiência alimentar (Coffey e Cromwell, 2001). Estudos também mostraram que as imunoglobulinas presentes no plasma animal spray-dried são as responsáveis por esses efeitos, por reduzirem os danos à parede intestinal ocasionados por bactéria e vírus (Gatnau et al., 1995; Touchette et al., 2000ab). O objetivo deste trabalho foi verificar o efeito do plasma suíno ultrafiltrado spray-dried, associado a um acidificante comercial, fornecidos na água de bebida, para a recuperação de leitões com sinais clínicos da SMDS.

\section{MATERIAL E MÉTODOS}

Utilizaram-se 40 leitões que apresentavam sinais clínicos da SMDS, selecionados em uma granja comercial de terminação com diagnóstico positivo para o PVC2 (histopatologia e PCR). Esses leitões eram de várias origens e foram alojados na terminação, com média de idade de 63 dias e selecionados 20 dias após, considerando os sinais clínicos apresentados. Os leitões selecionados foram transferidos para instalações isoladas onde teve início o experimento, com duração de 40 dias.

Utilizou-se o delineamento experimental aleatório com quatro tratamentos e 10 leitões cada: no T1 receberam água clorada à vontade (controle); no T2, solução com 2,5\% de plasma sangüíneo spray dried diluído em água; no T3, acidificante $\left(\mathrm{Selko}^{\mathbb{B}}\right)$ diluído em água na dosagem de $12 \mathrm{ml} / 101$; e, no T4, solução com $2,5 \%$ de plasma sangüíneo spray dried e o acidificante na dose de $12 \mathrm{ml} / 1$, diluídos em água para atingir o $\mathrm{pH}$ final próximo a 4,5 .

As respectivas soluções foram preparadas duas vezes ao dia, mantidas em balde graduado com capacidade para 201 e fornecidas aos leitões durante 14 dias no seguinte esquema: das 8 às 17 horas foi fornecida somente a solução do tratamento, em bebedouro de PVC de $0,8 \mathrm{~m}$ de comprimento e $150 \mathrm{~mm}$ de diâmetro, sendo a água dos bebedouros suprimida. Às 17 horas de cada dia, os bebedouros de PVC eram abastecidos com as respectivas soluções, e a água dos bebedouros liberada até a manhã do dia seguinte. A água usada como bebida era clorada e fornecida em bebedouro tipo bite ball. Todos os leitões receberam ração de crescimento à vontade em comedouro semi-automático de alumínio. Durante o experimento, nenhum produto antimicrobiano injetável ou oral foi utilizado.

As variáveis avaliadas foram: $\mathrm{pH}$ das soluções no tempo 0 e às 8,16 e 24 após a preparação, utilizando-se um potenciômetro; consumo diário das soluções; ganho de peso diário; consumo de ração; condição clínica dos leitões a cada sete dias; presença de anticorpos anti-PCV2 no soro colhido no dia do sacrifício dos leitões, utilizando-se a técnica de imunocitoquímica (Gava et al., 2005a); quadro anátomohistopatológico e de imunoistoquímica para PCV2 de $50 \%$ dos animais aos 28 dias e dos restantes aos 40 dias do início do experimento (Gava et al., 2005b), utilizando-se a técnica da avidina-biotina-peroxidase $^{1}$ e anticorpo policlonal anti-ORF2 produzido em coelho e taxa de mortalidade.

\footnotetext{
${ }^{1}$ Vectastain ${ }^{\circledR}$ ABC kit - Vector Laboratories Ltd. -
} Peteborough, Inglaterra. 
A análise de desempenho foi realizada pela teoria de modelos mistos, considerando os efeitos de tratamento e período experimental e 16 estruturas de matriz de variâncias e covariâncias, por meio do procedimento MIXED do SAS (System..., 2001), utilizando a macro proposta por Xavier (2000). A matriz de covariâncias foi escolhida com base no critério de informação de Akaike (AIC). Para as dados clínicos e patológicos utilizou-se o teste exato de Fisher.

\section{RESULTADOS E DISCUSSÃO}

$\mathrm{O}$ pH das soluções foi mais elevado no T1 e mais baixo no T3, porém os valores para cada solução mantiveram-se estáveis nas 24 horas avaliadas após a preparação (Fig. 1). O pH da solução de plasma e ácido (T4) manteve-se entre 4,41 e 4,63 , atendendo o objetivo do experimento de mantê-lo próximo a 4,5. $\mathrm{O} \mathrm{pH}$ da solução contendo apenas o ácido (T3) ficou bastante baixo. O consumo médio diário individual das soluções variou entre os tratamentos (Fig. 2), sendo maior nos leitões controle (T1) e menor naqueles que receberam apenas plasma (T2), provavelmente, porque esta solução era menos atrativa que as demais, conforme verificado pelo comportamento dos leitões. Os leitões do T2 apresentaram um pico de consumo da solução no $10^{\circ}$ dia do experimento, sem explicação lógica.

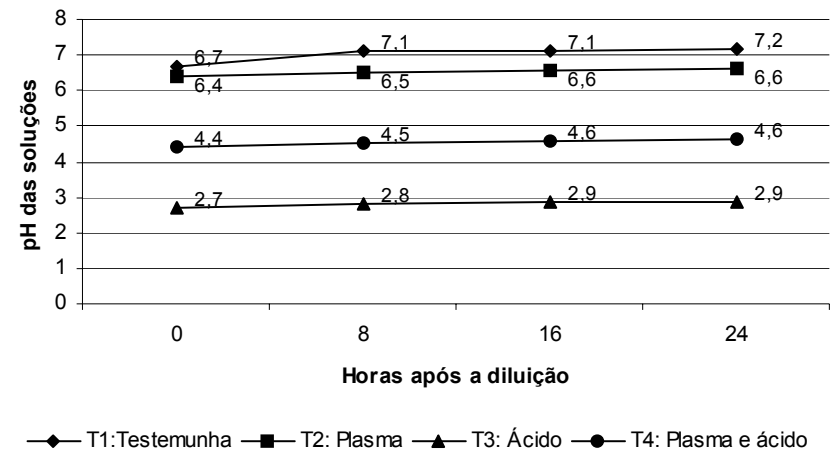

Figura 1. Valores de $\mathrm{pH}$ das soluções usadas nos tratamentos (média de três repetições) de leitões durante 24 horas após preparadas.

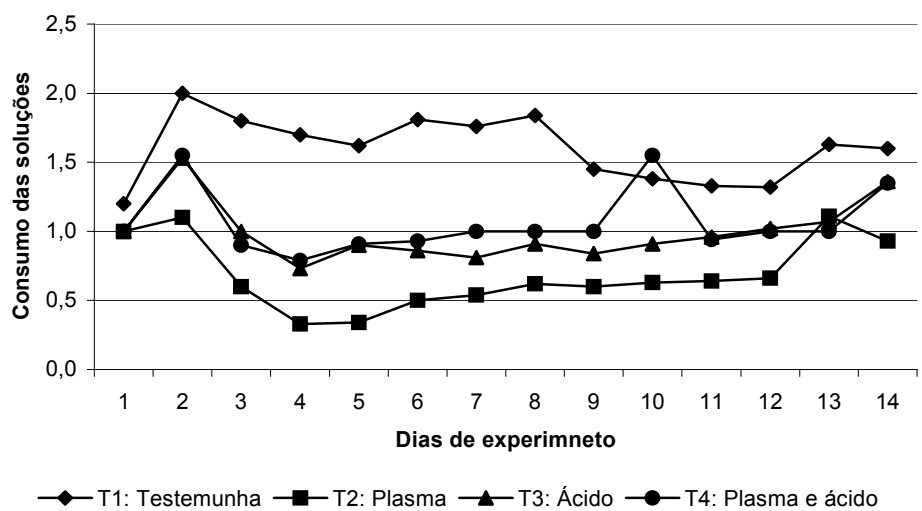

Figura 2. Consumo médio diário das soluções usados nos tratamentos de leitões nos primeiros 14 dias de experimento. 
Não houve diferença $(\mathrm{P}>0,05)$ entre os tratamentos no peso vivo (Tab. 1) e consumo de ração (Tab. 2). Os leitões do T3 foram os mais leves no final do experimento e também foram os que ingeriram menor quantidade da solução (Fig. 2). Embora não tenha sido possível realizar a análise estatística para a variável conversão alimentar, uma vez que não havia repetição, o resultado numérico foi mais baixo nos leitões que receberam o plasma e o ácido (T4), especialmente nos primeiros 14 dias de experimento (Tab. 1).

Tabela 1. Peso vivo e conversão alimentar dos leitões, segundo os tratamentos (T), por período acumulado do experimento

\begin{tabular}{cccccccccccc}
\hline & \multicolumn{4}{c}{ T } & \multicolumn{3}{c}{ Período (dias)/peso vivo médio $(\mathrm{kg})$} & \multicolumn{4}{c}{ Período (dias)/conversão alimentar } \\
\cline { 2 - 12 } & 0 & 7 & 14 & 21 & 28 & 40 & 7 & 14 & 21 & 28 & 40 \\
\hline T1 & 18,3 & 21,0 & 24,0 & 26,7 & 30,0 & 38,5 & 2,05 & 1,99 & 2,14 & 2,11 & 2,09 \\
T2 & 18,3 & 20,4 & 23,2 & 27,1 & 30,3 & 38,2 & 2,34 & 2,05 & 2,01 & 2,08 & 2,12 \\
T3 & 18,2 & 20,0 & 21,7 & 24,1 & 26,0 & 31,8 & 2,68 & 2,40 & 2,35 & 2,36 & 2,35 \\
T4 & 18,2 & 21,3 & 24,4 & 28,0 & 31,1 & 39,2 & 1,71 & 1,83 & 1,92 & 2,01 & 2,08
\end{tabular}

Não houve diferença estatística entre os tratamentos na variável peso vivo em todos os períodos pelo teste $\mathrm{F}$ para modelos mistos.

T1: controle; T2: plasma; T3: acidificante; T4: plasma + acidificante.

Tabela 2. Consumo de ração $(\mathrm{kg})$ pelos leitões, segundo os tratamentos $(\mathrm{T})$, por período acumulado até o final do experimento

\begin{tabular}{cccccc}
\hline \multirow{2}{*}{$\mathrm{T}$} & \multicolumn{5}{c}{ Dias de experimento } \\
\cline { 2 - 6 } & 7 & 14 & 21 & 28 & 40 \\
\hline T1 & 5,53 & 11,26 & 18,92 & 26,34 & 45,83 \\
T2 & 5,31 & 11,64 & 19,84 & 27,96 & 45,37 \\
T3 & 5,50 & 11,02 & 18,61 & 26,74 & 43,75 \\
T4 & 5,42 & 11,47 & 19,68 & 27,59 & 46,91 \\
\hline
\end{tabular}

Não houve diferença estatística entre os tratamentos pelo teste $\mathrm{F}$ para modelos mistos.

T1: controle; T2: plasma; T3: acidificante; T4: plasma + acidificante.

Não houve diferença estatística significativa entre os tratamentos na avaliação clínica (Tab. 3), nos exames de necropsia (Tab. 4) e no exame histológico (Tab. 5) para a SMDS, nos diferentes momentos avaliados. A maior freqüência de lesões histológicas encontradas foi depleção linfóide, pneumonia intersticial e nefrite linfohistiocitárioa (Tab. 6). No exame individual dos leitões, apenas quatro apresentaram pequena quantidade de antígeno nos tecidos na IHQ, realizada no dia do sacrifício, porém todos tinham anticorpos anti-PCV2 no soro e lesões histológicas nos tecidos, independente do tratamento (Tab. 7). Isso indica que todos os leitões sofreram infecção e doença pelo PCV2, porém na maioria deles o vírus não se encontrava mais nos tecidos alvos. Lesões macroscópicas associadas à SMDS foram encontradas em 15 animais, sendo cinco, três, três e quatro dos tratamentos $1,2,3$ e 4 , respectivamente. O achado mais freqüente, observado em 11 desses leitões, foi a presença de fibrina ou fibrose nas serosas (poliserosite e/ou pleurite e/ou peritonite) em diferentes estágios evolutivos e com gravidade variável.

Apesar da baixa freqüência de PCV2 nos tecidos, verificada pelo exame de IHQ (Tab. 7), observou-se elevada freqüência de lesões em alguns órgãos compatíveis com a SMDS (Zanella e Morés, 2003), independente do tratamento. 
Tabela 3. Gravidade da doença clínica em leitões compatível com a síndrome multissistêmica do definhamento, nos diferentes dias de avaliação

\begin{tabular}{|c|c|c|c|c|c|c|c|c|c|c|c|c|c|c|c|c|c|c|c|c|}
\hline \multirow{3}{*}{ T } & \multicolumn{20}{|c|}{ Período/gravidade da situação clínica*/número de suínos em cada graduação } \\
\hline & \multicolumn{4}{|c|}{ Início } & \multicolumn{4}{|c|}{7 dias } & \multicolumn{4}{|c|}{14 dias } & \multicolumn{4}{|c|}{21 dias } & \multicolumn{4}{|c|}{28 dias } \\
\hline & 0 & 1 & 2 & 3 & 0 & 1 & 2 & 3 & 0 & 1 & 2 & 3 & 0 & 1 & 2 & 3 & 0 & 1 & 2 & 3 \\
\hline T1 & 0 & 2 & 5 & 3 & 0 & 5 & 2 & 3 & 0 & 5 & 3 & 2 & 0 & 6 & 2 & 1 & 0 & 7 & 1 & 1 \\
\hline $\mathrm{T} 2$ & 0 & 3 & 5 & 2 & 1 & 3 & 3 & 0 & 0 & 4 & 5 & 0 & 1 & 6 & 2 & 0 & 2 & 7 & 0 & 0 \\
\hline T3 & 0 & 3 & 4 & 3 & 0 & 5 & 1 & 3 & 0 & 4 & 1 & 2 & 0 & 5 & 1 & 2 & 2 & 4 & 0 & 1 \\
\hline $\mathrm{T} 4$ & 0 & 4 & 4 & 2 & 0 & 7 & 2 & 1 & 1 & 7 & 1 & 1 & 3 & 5 & 1 & 0 & 4 & 5 & 0 & 0 \\
\hline
\end{tabular}

*0: normal; 1: leve; 2: moderado; 3: grave. T: tratamento.

Não houve diferença estatística entre os tratamentos pelo teste exato de Fisher.

T1: controle; T2: plasma; T3: acidificante; T4: plasma + acidificante.

Tabela 4. Achados de necropsia dos leitões mortos e/ou sacrificados segundo os tratamentos (T)

\begin{tabular}{lcccc}
\hline Variável & $\mathrm{T}_{1}$ & $\mathrm{~T}_{2}$ & $\mathrm{~T}_{3}$ & $\mathrm{~T}_{4}$ \\
\hline Definhamento da carcaça & $4 / 10^{*}$ & $2 / 10$ & $4 / 10$ & $1 / 10$ \\
Palidez da carcaça & $1 / 10$ & $2 / 10$ & $3 / 10$ & $1 / 10$ \\
Icterícia da carcaça & $1 / 10$ & $1 / 10$ & $1 / 10$ & $0 / 10$ \\
Conteúdo fluído no intestino grosso & $3 / 10$ & $3 / 10$ & $2 / 10$ & $2 / 10$ \\
Pulmão não colabado & $4 / 10$ & $3 / 10$ & $2 / 10$ & $1 / 10$ \\
Áreas de hepatização nos pulmões & $6 / 10$ & $4 / 10$ & $4 / 10$ & $4 / 10$ \\
Hiper ou hipotrofia dos linfonodos inguinais & $6 / 10$ & $3 / 10$ & $4 / 10$ & $5 / 10$ \\
Hiper ou hipotrofia dos linfonodos mesentéricos & $9 / 10$ & $7 / 10$ & $5 / 10$ & $6 / 10$ \\
Hipertrofia/linfonodos mediastínicos/ bronquiais & $3 / 10$ & $4 / 10$ & $3 / 10$ & $3 / 10$ \\
Hipotrofia do timo & $3 / 10$ & $4 / 10$ & $5 / 10$ & $1 / 10$ \\
Presença de úlcera gástrica & $3 / 10$ & $1 / 10$ & $3 / 10$ & $0 / 10$ \\
Hiperqueratose na região esofágea do estômago & $3 / 10$ & $6 / 10$ & $6 / 10$ & $4 / 10$ \\
Rins hipertróficos ou com pontos brancos focais & $5 / 10$ & $6 / 10$ & $6 / 10$ & $6 / 10$ \\
Lesão de pele & $0 / 10$ & $0 / 10$ & $0 / 10$ & $1 / 10$ \\
\hline
\end{tabular}

Não houve diferença estatística entre os tratamentos pelo teste exato de Fisher.

*Número de afetados/total examinados.

T1: controle; T2: plasma; T3: acidificante; T4: plasma + acidificante.

Tabela 5. Freqüência de leitões com lesões histológicas compatíveis com a síndrome multissistêmica do definhamento

\begin{tabular}{cllllllll}
\cline { 2 - 8 } $\mathrm{T}$ & \multicolumn{7}{c}{ Gravidade das lesões histológicas* } \\
\cline { 2 - 9 } & 0 & 1 & 2 & \multicolumn{6}{c}{ Leitões mortos/sacrificados até 28 dias* } & 0 & 1 & 2 & 3 \\
\hline $\mathrm{T} 1$ & 0 & 1 & 2 & 2 & 0 & 4 & 0 & 1 \\
$\mathrm{~T} 2$ & 0 & 2 & 2 & 1 & 0 & 2 & 3 & 0 \\
$\mathrm{~T} 3$ & 0 & 0 & 2 & 3 & 0 & 3 & 2 & 0 \\
$\mathrm{~T} 4$ & 0 & 3 & 2 & 0 & 0 & 4 & 1 & 0 \\
\hline
\end{tabular}

*0: normal; 1: leve; 2: moderado; 3: grave. T: tratamento.

Não houve diferença estatística entre os tratamentos pelo teste exato de Fisher.

T1: controle; T2: plasma; T3: acidificante; T4: plasma + acidificante. 
Tabela 6. Freqüência de leitões com diferentes graus de lesões histológicas, compatíveis com a síndrome multissistêmica do definhamento

\begin{tabular}{lccccc}
\hline \multirow{2}{*}{ Lesão histológica } & \multirow{2}{*}{$\mathrm{N}$} & \multicolumn{4}{c}{$\mathrm{N}^{\circ}$ de suínos/tratamento } \\
\cline { 3 - 6 } & & $\mathrm{T} 1$ & $\mathrm{~T} 2$ & $\mathrm{~T} 3$ & $\mathrm{~T} 4$ \\
\hline Depleção linfóide nos linfonodos & 10 & 5 & 7 & 6 & 4 \\
Células multinucleadas nos linfonodos & 10 & 0 & 2 & 1 & 0 \\
Corpúsculo de inclusão nos linfonodos & 10 & 0 & 0 & 1 & 1 \\
Pneumonia intersticial & 10 & 10 & 10 & 10 & 9 \\
Nefrite linfo-histiocitária & 10 & 10 & 9 & 10 & 10 \\
Depleção linfóide nas placas de Peyer & 10 & 5 & 5 & 6 & 4 \\
Depleção linfóide no timo* & 10 & 5 & 4 & 5 & 2 \\
\hline
\end{tabular}

Não houve diferença estatística entre os tratamentos pelo teste exato de Fisher.

*Em um suíno do T2 e em um do T4 este órgão não foi examinado.

T1: controle; T2: plasma; T3: acidificante; T4: plasma + acidificante.

Tabela 7. Exames sorológicos de imunocitoquímica (ICQ), histológicos e de imunoistoquímica (IHQ) individual dos leitões

\begin{tabular}{|c|c|c|c|c|c|c|c|c|c|c|c|c|c|}
\hline \multirow{2}{*}{ Suíno* } & \multirow{2}{*}{$\mathrm{T}$} & \multirow{2}{*}{ ICQ } & \multicolumn{4}{|c|}{ Linfonodos } & \multicolumn{4}{|c|}{ Pulmões } & \multicolumn{3}{|c|}{ Timo } \\
\hline & & & $\mathrm{DL}$ & $\mathrm{CM}$ & CI & IHQ & PI & $\mathrm{PE}$ & PL & IHQ & DL & SR & IHQ \\
\hline 55 & & +++ & + & - & - & - & + & + & - & - & - & + & - \\
\hline 56 & & ++ & - & - & - & + & + & + & - & - & - & + & - \\
\hline 59 & & ++ & +++ & - & - & - & + & + & + & - & +++ & - & - \\
\hline 61 & $\mathrm{~T} 1$ & +++ & - & - & - & - & ++ & + & - & - & + & + & - \\
\hline 66 & 11 & +++ & + & - & - & - & +++ & + & - & - & + & + & - \\
\hline 70 & & + & + & - & - & - & ++ & + & + & - & ++ & - & - \\
\hline 86 & & +++ & - & - & - & - & + & - & - & - & - & + & - \\
\hline 91 & & ++ & ++ & - & - & - & +++ & + & - & - & + & + & - \\
\hline 93 & & ++ & - & - & - & - & + & + & + & - & - & + & - \\
\hline 53 & & +++ & + & - & - & - & +++ & + & + & - & + & + & - \\
\hline 60 & & ++ & + & + & - & - & + & + & - & - & - & + & - \\
\hline 67 & & ++ & + & - & - & - & +++ & - & - & - & + & + & - \\
\hline 68 & $\mathrm{~T} 2$ & ++ & - & + & - & - & + & - & - & - & - & + & - \\
\hline 73 & & ++ & - & - & - & + & ++ & + & - & - & - & + & - \\
\hline 88 & & ++ & + & - & - & - & + & + & - & - & - & + & - \\
\hline 474 & & + & + & - & - & - & + & - & - & - & - & + & - \\
\hline 52 & & ++++ & - & - & - & - & + & + & - & - & - & + & - \\
\hline 71 & & + & - & - & - & - & + & - & + & - & - & + & - \\
\hline 72 & $\mathrm{~T} 3$ & ++ & - & - & - & - & +++ & - & - & - & + & + & - \\
\hline 75 & & ++ & + & - & - & - & + & - & - & - & - & + & - \\
\hline 94 & & ++ & ++ & - & - & - & ++ & + & - & - & - & + & - \\
\hline 97 & & ++ & - & - & - & + & + & + & - & - & - & + & - \\
\hline 54 & & +++ & - & - & - & - & + & - & - & - & - & + & - \\
\hline 69 & & ++ & - & - & - & - & +++ & - & - & - & - & + & + \\
\hline 74 & & ++ & + & - & - & - & +++ & + & + & - & - & - & - \\
\hline 87 & T & +++ & - & - & - & - & - & + & - & + & - & - & - \\
\hline 90 & 14 & ++ & + & - & - & - & +++ & - & - & - & - & + & - \\
\hline 96 & & ++ & - & - & - & - & + & + & - & - & - & + & - \\
\hline 98 & & ++ & - & - & - & - & + & - & - & - & - & + & - \\
\hline 99 & & ++ & - & - & - & - & ++ & - & - & - & + & + & - \\
\hline 100 & & ++ & + & - & - & - & +++ & - & - & - & + & + & - \\
\hline
\end{tabular}

*Alguns suínos/tratamento não foram avaliados porque não havia o soro para exame ICQ.

DL: depleção linfóide; CM: formação de células multinucleadas; CI: presença de corpúsculo de inclusões intracitoplasmática; PI: pneumonia intersticial: PE: pneumonia exsudativa; PL: pleurite; SR: sinais de regeneração. T: tratamento.

T1: controle; T2: plasma; T3: acidificante; T4: plasma + acidificante.

+++ : positivo acentuado, ++ : positivo moderado, + : positivo leve, -: negativo. 
A inclusão de plasma animal spray dried na dieta de leitões desmamados sadios estimula o consumo de alimento, aumenta a taxa de ganho de peso e melhora a conversão alimentar (Coffey e Cromwell, 2001). O modo de ação que elícita essa resposta não está totalmente esclarecido. Cain e Zimmermam (1997) demonstraram que o plasma spray dried reduz o dano à mucosa intestinal ocasionado por bactérias e vírus. Outros trabalhos verificaram que o principal responsável por esse efeito benéfico do plasma spray dried é a fração protéica de alto peso molecular, ou seja, as imunoglobulinas (Gatnau et al., 1995). O método usado na elaboração do plasma spray dried preserva as atividades das imunoglobulinas nele contidas (Gatnau et al., 1989). Também, tem sido demonstrado que o plasma spray dried deixa os animais imunologicamente mais competentes (Touchette et al., 2000ab). Em experimentos anteriores com plasma animal spray dried diluído em água e fornecido aos leitões de creche, foram observados efeitos protetores em infecções por rotavirus (Harrel et al. 2000) e por Escherichia coli (Borg et al., 1999). Hipoteticamente, é possível que o efeito benéfico do plasma spray dried seja significativo se fornecido aos leitões preventivamente em granjas onde a SMDS esteja ocorrendo e isso deve ser testado. É importante salientar, ainda, que o envolvimento das serosas (pleura e peritônio) e do intestino grosso foi freqüente, independente do tratamento.

A mortalidade de leitões foi baixa em todos os tratamentos: 1 leitão no T1, 1 no T2, 3 no T3 e 1 no T4. Isso, de certa forma, foi uma surpresa porque, segundo informações do proprietário onde os animais foram obtidos, a maioria deles iria morrer em conseqüência da SMDS. Isso pode ser uma das causas prováveis de não ter sido detectado diferença estatística entre os tratamentos em muitas das variáveis avaliadas. A alta sobrevivência dos leitões em todos os tratamentos pode ser devido à retirada deles das baias originais, reduzindo a competição com os leitões saudáveis companheiros de baia e ao fato de eles terem sido alojados em ambiente melhor, com menor lotação e menor pressão de infecção. Com isso foram reduzidos alguns fatores de risco associados à SMDS, que são importantes no desenvolvimento da enfermidade (Madec et al., 1999).
Os dados obtidos neste experimento indicam que os leitões sofreram a infecção pelo PCV2, desenvolveram sinais clínicos e lesões compatíveis com a SMDS, porém a maioria deles apresentou melhora clínica, independente do tratamento, sem medicação quimioterápica. Isso sugere que a retirada dos leitões das baias de origem, alojando-os em local com menor densidade animal e melhor ambiente, é importante para a recuperação da saúde.

\section{CONCLUSÕES}

$\mathrm{O}$ pH da solução com 2,5\% de plasma sangüíneo $+1,2 \mathrm{ml} / 1$ do acidificante se estabilizou em torno 4,5 e manteve-se estável nas 24 horas após sua preparação. Os leitões que receberam o plasma sem o acidificante ingeriram menos solução que os demais, provavelmente por rejeição. O plasma spray dried associado ao ácido não melhoraram a situação clínica-patológica de leitões com sinais clínicos da SMDS. A retirada dos leitões das instalações de origem, reduzindo a pressão de infecção e os fatores de risco, melhorou a sobrevivência desses animais, mesmo sem o uso de qualquer medicação.

\section{REFERÊNCIAS BIBLIOGRÁFICAS}

BORG, B.S.; CAMPBELL, J.M.; KOEHNK, H. et al. Effects of a water soluble plasma protein product on weaning pig performance and health with and without Escherichia coli challenge. In: ALLEN D. LEMAN SWINE CONFERENCE, 26., 1999, Ames. Proceedings... Ames: [s.n.] 1999. p. 23-24.

CAIN, C.M.; ZIMMERMANN, D.R. Effects spray dried plasma (SDP) on fecal shedding of hemolytic Escherichia coli (HEC) and rotavirus by pigs in a segregated early-weaned (SEW) environment. J. Anim. Sci., v.75, suppl. 1, p.61, 1997.

COFFEY, R.D.; CROMWELL, G.L. Use of spray-dried animal plasma in diets for weaning pigs. Pig News Inf., v.22, p.39-43, 2001.

GATNAU, R.; PREM, P.; ZIMMERMAN. D. Spray dried porcine plasma as a souce of immunoglobulins for newborn pigs. J. Anim. Sci., v.67, suppl. 1, p.244, 1989. 
GATNAU, R.; CAIN. C.; DREW, M. et al. Mode of action of sprey-dried porcine plasma in weaning pig. J. Anim. Sci., v.72, suppl. 1, p. 82. 1995.

GAVA, D.; CIACCI-ZANELLA, J. R.; MORÉS, $\mathrm{N}$. et al. Utilização da técnica de imunocitoquímica (ICQ) para detecção de anticorpos contra o circovirus tipo 2 (PCV2) em soro suíno. In: CONGRESSO BRASILEIRO DE VETERINÁRIOS ESPECIALISTAS EM SUÍNOS, 12., 2005, Fortaleza. Anais... Fortaleza: ABRAVES, 2005. p.115-116.

GAVA, D.; MORÉS, N.; CIACCI-ZANELLA, J. $R$. et al. Padronização de uma técnica de imunohistoquímica (IHQ) em cortes histológicos para detecção de circovirus tipo 2 (PCV2) utilizando anticorpo monoclonal. In.: CONGRESSO BRASILEIRO DE VETERINÁRIOS ESPECIALISTAS EM SUÍNOS, 12., 2005, Fortaleza. Anais... Fortaleza: ABRAVES, 2005. p.113-114.

HARDING, J.C.S.; CLARK, E.G.; STROKAPPE, J.H. et al. Postweaning multisystemic wasting syndrome: epidemiology and clinical presentation. Swine Health Prod., v.6, p.249-254, 1998.

HARRELL, R.J.; MOON, H.K.; WEAVER, E.M. et al. Effets of animal plasma proteins on intestinal recovery of neonatal pigs infected with rotavirus. FASEB J., v.14, p. A728, 2000.

MADEC, F.; EVENO, É.; MORVAN, P. et al. La maladie de eámaigrissement du porcelet (MAP) en France. Aspecs descriptifs, impact en élevage. J. Res. Porcine France, v.31, p.347-354, 1999.
MORÉS, N. Impacto econômico da circovirose na produção de suínos. In. SEMINÁRIO INTERNACIONAL DE AVES E SUÍNOS, 4., 2005, Florianópolis. Anais... Concórdia: Embrapa Suínos e Aves, 2005. v.5, p.9-13.

SYSTEM for Microsoft windows: release 8.2. Cary, NC, SAS Institute, 1999-2001. (cd-rom).

TOUCHETTE K.J.; ALLEE, G.L.; MATTERI, R.L. et al. Feeding spray-dried plasma decreases the activation of the hypothalamic-pituitaryadrenal axis. J. Anim. Sci., v.78, suppl. 1, p.181, 2000a.

TOUCHETTE K.J.; CARROL, J.A.; ALLEE, G.L. et al. Feeding spray-dried plasma (SDP) alters the immunological response of weaned pig to a lipopolysaccharide (LPS) challenge. J. Anim. Sci., v.78, suppl. 2, p.63, 2000 b.

XAVIER, L.H. Modelos univariado e multivariado para análise de medidas repetidas e verificação da acurácia do modelo univariado por meio de simulação. 2000. 91f. Dissertação (Mestrado) - Escola Superior de Agricultura Luiz de Queiroz, Universidade de São Paulo, Piracicaba.

ZANELLA, J. R. C.; MORÉS, N. Síndrome multissistêmica do definamento do leitão desmamado (SMDLD) causada por circovírus suíno. In: CONGRESO MERCOSUR DE PRODUCCIÓN PORCINA, 1., 2000, Buenos Aires. Memória... Buenos Aires: Universidade de Buenos Aires, 2000. p.EIP16-EIP16.

ZANELLA, J.C.; MORÉS, N. Circovirose suína. Concórdia: Embrapa Suínos e Aves, 2003. 12p. (Circular Técnica, 37). 